\title{
Arquitetura e o mundo
}

\author{
Leandro Medrano
}

O professor Hashim Sarkis, que atualmente é diretor da School of Architecture and Planning do MIT, esteve recentemente na FAUUSP para apresentar a palestra The world according to architecture. No mesmo período, inaugurou exposição com ilustrações e textos relacionados aos temas da palestra, locada no átrio central do Edifíco Vilanova Artigas. Arquiteto reconhecido pela crítica especializada e autor de diversos livros e artigos acadêmicos, suas pesquisas difundiram-se com maior intensidade a partir das publicações da revista New Geographies, iniciada em 2003, na GSD Harvard. A principal questão que unifica os temas tratados na New Geographies e os estudos do professor Sarkis é a ideia de um mundo urbano unificado - uma espacialidade global mediada pela arquitetura - e as consequências desse fenômeno na sociedade contemporânea. Aos arquitetos e urbanistas, ou mesmo aos designers, essa nova geografia geral implicaria nas estratégias de desenho dos espaços das atividades cotidianas do homem.

\begin{abstract}
Increasingly, architects and planners are being compelled to address and transform larger contexts and to give these contexts more legible and expressive form. New problems are being placed on designers' agendas (e.g. infrastructure, urban systems, regional and rural questions). Problems that had been confined to the domains of engineering, ecology, or regional planning are now looking for articulation by design (SARKIS, 2011 p.107)
\end{abstract}

A especificidade dos temas abordados na New Geographies se daria na busca pela correlação entre as formas experimentadas nas disciplinas que operam em relação ao espaço - arquitetura, desenho urbano, urbanismo, design etc. - e às incertas realidades contemporâneas. Desse modo, busca-se os sentidos dessa relação dialética que ocorre nas mais diversas escalas de intervenção. Ou seja, compreender o modo com o qual essas disciplinas organizam seus processos de projetação, sua epistemologia ou história, e ainda os significados decorrentes do impacto físico de suas interferências nas dinâmicas do cotidiano. 0 que nos levaria a entender o espaço-projetado como resultado desse complexo modelo de apropriação e transformação que, no limite, abrangeria todo o território do mundo.

Esse discurso se problematiza, pelo menos em seus vetores de progressividade, quando considerados os entraves sociais e políticos que solapamos nos dias de hoje, no Brasil e no exterior. No caso brasileiro, a dualidade social que historicamente caracterizou o espaço-social (e a forma) das cidades tem intensificado suas contradições congênitas - marcadas pela expectativa de vir a ser uma grande nação moderna e multicultural e os conflitos ensejados pelo acirramento da cisão entre a pobreza e a riqueza extrema, sinais indeléveis do atraso. Essa dualidade é notória em nosso processo de urbanização de favelas e condomínios murados, de territoriedades singulares e edifícios genéricos, de pouco apreço pelo que é público, coletivo ou comum. Uma realidade urbana na qual as estratégias de desenho disciplinares pouco colaboraram com alternativas, sejam elas na escala do desenho do objeto ou da cidade. Ao contrário, não são raros os exemplos de projetos que se afirmam justamente em virtude dessa peculiar condição - a casa "moderna" frente à natureza, o palácio frente à precariedade urbana, o desenho astuto frente a uma incipiente base tecnológica.

Ademais, os tensionamentos políticos que buscaram afrontar a desigualdade e o subdesenvolvimento como elementos estruturais da versão brasileira desse capitalismo desigual e combinado não encontraram no projeto do território, ou em sua forma espacial, alternativas aos esquemas empregados pelos padrões autoritários e excludentes de gestão. Ou seja, do extinto Banco Nacional da Habitação (BNH), que ditava a política habitacional na ditadura militar dos anos 1970, ao Programa Minha Casa Minha Vida, a condição urbana das cidades brasileiras não acompanharam os avanços econômicos, culturais e sociais que marcaram a sociedade brasileira na primeira década do século 21. 
Por outro lado, os espaços de segregação, até então mais intensos e evidentes nos países em desenvolvimento, agora também afligem os territórios que pareciam procurar equacionar seus problemas sociais mais prementes. Muros em escala continental, cidades-alojamentos e rotas de refugiados, bem como outros entraves resultantes de modelos de segregação passam a atingir uma dimensão global, visto que pobreza e violência não mais confinam-se aos lugares apartados dos bens de consumo e das riquezas promovidas pela financeirização em escala globalizada.

Nesse contexto, os temas que envolvem as disciplinas tratadas na Revista Pós devem reconhecer o aumento da complexidade de suas dinâmicas internas, no sentido de encontrar respostas às externalidades da dramática vida cotidiana atual e às questões decorrentes de um território urbano global. Uma saída às forças de regressão que parecem recrudescer por todo lado.

Os artigos selecionados para a edição número 40 da Revista Pós, pela diversidade das questões tratadas e das metodologias empregadas, expressam a complexidade dos temas em debate nos os campos da arquitetura, do urbanismo e do design. De tal maneira que não compõem uma unidade, mas convergem no que tange a utilização de instrumentos de pesquisa para consubstanciar tanto fundamentos teóricos quanto práticas cotidianas.

O ensaio A presença da lentidão na cidade e seus efeitos no pensamento urbano contemporâneo, de Thiago de Araújo, discute a possibilidade de uma outra ordem cinética às cidades, como forma de contrapor a aceleração do tempo imposta pelo neoliberalismo. Tal inversão propiciaria uma "dilatação do espaço-temporal", em sentido oposto ao que se verifica no mundo - e por isso mesmo promissor.

A territorialização indigenista e seu confronto com os processos de urbanização tradicional das sociedades ocidentais é o tema central do artigo 0 lote e a maloca: territorialização indigenista, mudanças no saber - fazer arquitetônico e a evolução da paisagem nas aldeias indígenas. Um estudo de caso a partir dos kaingáng, do geógrafo Sandoval dos Santos Amparo. Como meio de reflexão, busca a correlação entre o lote - unidade espacial característica da urbanização brasileira - e a maloca - referência principal da habitação tradicional indígena. Para o autor, se o lote delimitaria a geometria na qual as habitações brasileiras deveriam edificar-se para assim conformar o espaço urbano das cidades, a maloca seria uma versão deslocada desse sistema ocidental e colonizador de ocupação territorial. Ademais, a maloca poderia indicar uma predação simbólica da alteridade em direção à criação de novas narrativas a esses sujeitos históricos, e não apenas uma submissão passiva às normativas da produção do espaço das sociedades capitalistas ocidentais.

O urbanista italiano Bernardo Secchié é tema do artigo As ideias-guias de Bernardo Secchi, de autoria de Milena D'Ayala Valva. O texto enfatiza a relevância dos aportes teóricos desse urbanista, principalmente a partir dos anos 1980, quando reconhece que a Europa deveria rever o modelo urbanístico adotado desde o fim da Segunda Guerra - baseado em processos de expansão - e investir no reconhecimento crítico do território existente, o que levaria a processos de transformação. Destaca-se a capacidade de Bernardo Secchi em estabelecer relações entre as teorias e as práticas do urbanismo, o que o levou a reconhecer os limites dos modelos de atuação da disciplina em relação às cidades contemporâneas, e por isso propor novos aportes teóricos e processos de projeto que se tornaram referência em todo o mundo.

O artigo Planejamento criativo e sustentabilidade social, de Tatiane Oliveira Teles, procura explorar os conceitos do chamado "Planejamento Criativo" por meio do estudo crítico do projeto "Cantinho do Céu", que trata de uma ocupação ilegalmente assentada em área ambientalmente protegida, nas margens da Represa Billings, na cidade de São Paulo. A complexidade dos temas tratados, principalmente quando consideradas as demandas habitacionais da cidade de São Paulo, segundo a autora, direcionou as intervenções urbanas às técnicas do "Planejamento Criativo" - que atua na mudança de perspectiva histórica do local, e não na sua transformação imediata.

Por meio do estudo da paisagem, da forma urbana, e dos espaços livres da cidade de Patos de Minas, 0 artigo $O$ uso das unidades de paisagem como ferramenta metodológica para análise do 
sistema de espaços livres, de Nayara Cristina Rosa Amorim e Glauco de Paula Cocozza, procura compreender o Sistema de Espaços Livres dessa cidade. Utilizando metodologia baseada na identificação das Unidades de Paisagem, a pesquisa indica as falhas no planejamento urbano da cidade no que diz respeito ao projeto, manutenção e gestão dos seus espaços livres.

A relação entre avaliação do impacto ambiental das escolhas construtivas e tecnológicas dos projetos de edifícios e a utilização da plataforma Building Information Modelling (BIM) é o tema do artigo Aplicação da modelagem de informação da construção BIM para a realização de estudos de avaliação de ciclo de vida de edifícios, de Cristiane Bueno e Márcio Minto Fabricio. Além de uma extensa revisão da bibliografia relacionada ao tema, os autores apresentam uma análise de diversos plug-in dedicados ao tema. Seus resultados devem auxiliar o desenvolvimento dessa importante ferramenta de projeto, ainda pouco explorada no que diz respeito aos processos de projeto nas áreas da arquitetura, urbanismo e design.

A autora Ana Carolina Bierrenbach analisa a arquitetura dos clubes da cidade de Salvador, na Bahia, construídos durante o século 20. Demonstra como a arquitetura "moderna" desses clubes é substituída, no passar dos anos, por outras construções que buscam acompanhar a "moda arquitetônica". Segundo a autora, a ausência de iniciativas destinadas à conservação da memória material e cultural desses clubes fragiliza suas relações com a história recente da sociedade local.

A bibliografia decorrente da obra do arquiteto João Vilanova Artigas é o tema do artigo Glosando a bibliografia sobre Vilanova Artigas, de Fernando Guillermo Vázquez Ramos. 0 autor faz uma vasta pesquisa na literatura existente sobre o tema e a organiza segundo o meio de divulgação, fundamento conceitual e estratégia metodológica. Conclui que apesar do arquiteto Vilanova Artigas ser reconhecidamente uma das personalidades mais importantes da arquitetura brasileira do século 20 , os estudos relacionados à análise crítica das obras e as ideias desse arquiteto, ainda são poucos, e não exploram a totalidade de suas obras e conceitos. Trata-se de um campo de estudos que merece atenção da comunidade de pesquisadores dedicados à arquitetura brasileira.

A análise comparativa entre a obra do arquiteto norte-americano Frank Lloyd Wright e do arquiteto português Raul Lino é o tema do artigo Olhando a obra de Raul Lino, a pensar em Frank Lloyd Wright: partindo do arts \& crafts, com a natureza, o orgânico e a casa, de autoria do professor José Manuel Fernandes. Tal análise fundamenta-se nas bases teóricas e referenciais desses arquitetos, bem como nos "princípios de projeto" elaborados por eles. Como ponto de partida, tem-se o programa da casa unifamiliar, analisado por meio de alguns estudos de casos. 0 autor revela que, apesar das diferentes realidades culturais e circunstâncias históricas das obras desses arquitetos, algumas convergências podem ser identificadas, sobretudo na produção centrada entre 1900 a 1910.

Diretrizes para preservação do patrimônio industrial. Vila ferroviária de Mairinque / SP é título do artigo de autoria de Rafaela Rogato Silva e Eduardo Romero de Oliveira. Trata-se de uma análise pormenorizada do conjunto ferroviário existente na cidade de Mairinque e seu entorno. Revela que tanto as transformações na operação ferroviária quanto as distintas formas de proteção preservacionista não foram suficientes para a promoção efetiva de uma política de preservação voltada ao conjunto. Diagnóstico que reforçaria a importância da adoção de diretrizes patrimoniais nesse caso e em outros assemelhados.

O número 40 da Revista Pós ainda conta com duas resenhas: uma delas sobre exposição dedicada a Roberto Burle Marx, que foi exibida em 2016 no JewishMuseum de Nova York, resenha de Fernando Atique e Roseli Maria Martins D'Elbouxe, e outra sobre o livro Arte, Cultura e Cidade: aspectos estéticos-políticos contemporâneos, da professora Vera Pallamin, resenhado por Paolo Colosso com o título A produção de cultura urbana: práticas espaciais e imaginários em disputa.

Boa leitura!

Leandro Medrano

Editor-Chefe Revista PÓS

medrano@usp.br 